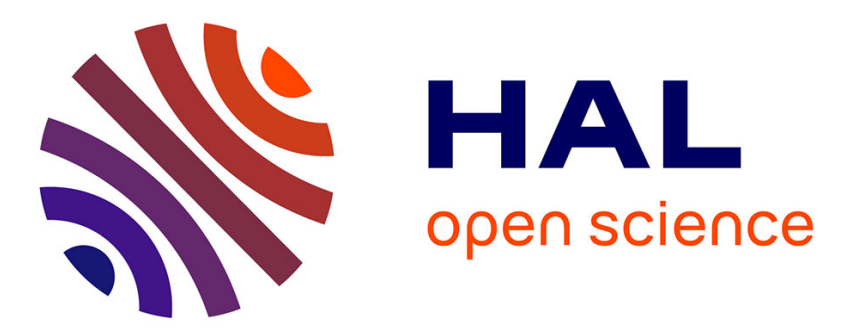

\title{
Individual differences in infant's emotional resonance to a peer in distress. Self-other awareness and emotion regulation
}

\author{
Elena Geangu, Oana Benga, Daniel Stahl, Tricia Striano
}

\section{To cite this version:}

Elena Geangu, Oana Benga, Daniel Stahl, Tricia Striano. Individual differences in infant's emotional resonance to a peer in distress. Self-other awareness and emotion regulation. Social Development, 2011, 20 (3), pp.450. 10.1111/j.1467-9507.2010.00596.x . hal-00613825

\section{HAL Id: hal-00613825 \\ https://hal.science/hal-00613825}

Submitted on 6 Aug 2011

HAL is a multi-disciplinary open access archive for the deposit and dissemination of scientific research documents, whether they are published or not. The documents may come from teaching and research institutions in France or abroad, or from public or private research centers.
L'archive ouverte pluridisciplinaire HAL, est destinée au dépôt et à la diffusion de documents scientifiques de niveau recherche, publiés ou non, émanant des établissements d'enseignement et de recherche français ou étrangers, des laboratoires publics ou privés. 


\section{Social Development}

Individual differences in infant's emotional resonance to a peer in distress. Self-other awareness and emotion regulation

\begin{tabular}{|r|l|}
\hline Journal: & Social Development \\
\hline Manuscript ID: & SODE-10-0005.R3 \\
\hline Manuscript Type: & Original Manuscript \\
\hline Keywords: & Empathy, Infancy, Emotion regulation, Self perception \\
\hline & \\
\hline
\end{tabular}

\section{S ScholaroNE" \\ Manuscript Central}




\begin{abstract}
In this study, relations between emotional resonance responses to another's distress, emotion regulation and self-other discrimination were investigated in infants 3-, 6-, and 9-month-old. We measured the emotional reactions to the pain cry of a peer, along with the ability to regulate emotions and to discriminate between self and other body movements. We found evidence that infants do regulate their emotional resonance responses to another's distress. This relation is age specific, with younger infants using more primitive self-soothing behaviors, while in older participants attentional based strategies relate to affect sharing reactions. Only 9-month-old infants have shown self-other differentiation abilities, and these were significantly connected to their emotions in response to a peer's distress. These findings have implications for our understanding of early empathy development.
\end{abstract}

Keywords: empathy, infancy, emotion regulation, self perception 
Individual differences in infant's emotional resonance to a peer in distress. Self-other awareness and emotion regulation.

Empathy related responses are essential for children's developing abilities to respond to their social partners in an altruistic manner (Eisenberg, Guthrie, Murphy, Shepard, Cumberland, \& Carlo, 1999). Once developed, these abilities tend to be manifested with consistency across time (Knafo, Zahn-Waxler, Van Hulle, Robinson, \& Rhee, 2008). Empathy as an emotional response stems from the comprehension of another's emotional state or condition, similar to what the other person is feeling or would be expected to feel (Eisenberg, Shea, Carlo, \& Knight, 1991). It is associated with at least minimal awareness that the source of one's own affect is the emotion observed in the other person (Decety \& Jackson, 2004; Hoffman, 2000). The "functional architecture" of human empathy encompasses several components, including affect sharing, self-other awareness, regulatory processes, and perspective taking (Decety \& Jackson, 2004). Among these, affect sharing or the ability to emotionally resonate to other's emotions seems to represent the core element of empathy (de Waal, 2006).

Emotional resonance is the first element of empathy to appear during ontogeny. It can be seen in the newborns' contagious crying reactions to the cry of another newborn (Field, Diego, HernandezReif, \& Fernandez, 2007; Sagi \& Hoffman, 1985; Simner, 1971). It has been hypothesized that later in development, this initial pure emotional contagion becomes associated with a growing differentiation between self and other, allowing for reactions that are more tuned into the other's state than one's own. Also, the infant is increasingly able to use regulatory strategies for modulating this emotional response to an adaptive level for both the self and conspecifics (Hoffman, 2000).

In general, it is considered that only around the age of 18-24 months children manifest such mature empathic reactions (Hoffman, 2000). One of the main arguments is that at this age children 
pass the classic test of mirror self-recognition which may index the existence of a self concept. In support of this argument, Zahn-Waxler, Radke-Yarrow, and Wagner (1992) provide some indirect evidence by showing that 23- to 25-month-olds who have higher levels of mirror self-recognition manifest more prosocial behaviors. In the same vein, Kärtner, Keller, Kleis, and Lamm (2004) show that a large percent of those 19-month-old children who manifest helping behaviors toward a distressed adult also recognize themselves in the mirror.

However, the perception of other's emotions induces in the observer a matching affective state as early as few days after birth, with newborns manifesting increased facial and vocal distress in response to the cry sound of another infant (Field et al., 2007; Martin \& Clark, 1982; Simner, 1971). Later in infancy, these affective resonance responses to others' emotions seem to persist. Haviland and Lelwica (1987) have shown that the perception of mother's expressions of joy and anger induces in 10week-old matching affect states. Importantly, in this study, the perception of persistent anger, but not positive emotion, resulted in increased affect sharing in half of the sample. Other's negative emotions (e.g., the pain cry of another infant) induce facial anger and sadness in 1-, 3-, 6-, and 9-month-old infants (Geangu, Benga, Stahl, \& Striano, 2010), and toddlers (Spinrad \& Stifter, 2006). Similarly, this type of stimulus triggers negative emotional reactions evident in both facial expressions and cardiac reactivity in kindergarten and school age children as well (Fabes, Eisenberg, Karbon, Troyer, \& Switzer, 1994; Zahn-Waxler, Friedman, \& Cummings, 1983).

Independent of empathy research, investigations concerning the ontogenesis of a sense of self suggest that well before the age of 2 , children develop a perceptual protorepresentation of the body which allows them to differentiate between self and others (Rochat \& Striano, 2000). Infancy is also the time for important developments of regulatory mechanisms (Calkins \& Hill, 2007; Kopp, 1982). One might thus reasonably think that the emotional resonance to another's distress as it is documented in infants might be interconnected with these other abilities. Scattered evidence supports this line of 
thought. Newborns discriminate between their own cry and the cry of another (Dondi, Simion, \& Caltran, 1999), and express more emotional contagion in response to the cry sound of a peer than in response to their own cry (Simner, 1971). Further, infants who better regulate their emotional arousal at the age of 4-months, show reduced affect sharing in response to a peer's distress at the age of 12 months (Ungerer, Dolby, Waters, Barnett, Kelk, \& Lewin, 1990). It thus seems that early emotional arousal is not pure contagion, rather it is associated with an awareness of the source of distress, and it might be regulated. The present study is designed to further investigate possible relations between emotional resonance to another's distress, self-other differentiation, and emotion regulation during infancy.

The development of a sense of self is a very dynamic process that starts early in infancy, and encompasses several aspects related to forming a primary representation of the bodily self and having a sense of self as a physical agent, as well as differentiating between self and others as intentional agents (Gergely, 2002; Rochat \& Striano, 2000). The early ability to discriminate the bodily self from others is based on an implicit intermodal body schema (Rochat \& Striano, 2000) that integrates information related to bodily space (Bahrick \& Watson, 1985; Schmuckler \& Fairhall, 2001), intermodal timing (Rochat, 1998; Rochat \& Morgan, 1995), and intermodal forms of action (Rochat \& Striano, 1999a). Newborns are successful in discriminating between self and other produced tactile stimulation (Rochat \& Hespos, 1997), and in altering self-produced action in order to obtain a certain outcome (i.e., to hear or see their mother) (DeCasper \& Fifer, 1980). By the age of 2 months, infants become sensitive to the relative matching of proprioception with other perceptual modalities, and seem to detect links between their sucking actions and the auditory consequences of this action, based on spatial and temporal matching (Rochat \& Striano, 1999b).

Around the age of 5-months there are signs of intermodal matching between proprioceptive and visual determinants of limb movements. At this age infants prefer to watch a video display of their own 
or of another infant non-contingent hand or leg movements, but not a video display of their own contingent hand or leg movement (Bahrick \& Watson, 1985; Rochat \& Morgan, 1995). Seven- and 9month-old infants seem to require less information about motion (Schmuckler \& Fairhall, 2001), and less perfect timing (Zmyj, Hauf, \& Striano, 2009) for establishing such a contingency, and they manifest a propensity for social initiatives towards others compared to their own image in the mirror. In conjunction, these data suggest that infants at this age do show a perceptual discrimination between self and others, even if they don't necessarily construe a representation of their own image (Rochat \& Striano, 2002). It is also around the age of 9-months, that children begin to understand others as having different intentional states than their own and to act upon them (Tomasello, 1995).

Little is known about if or how this increased self-other differentiation relates to the early observed emotional resonance. Importantly, work with newborns show that they selectively manifest contagious crying in response to another baby's cry, but not to their own cry (Simner, 1971; Field et al., 2007), suggesting that a relation between affect sharing and an incipient sense of self might be already present. Apart from work on infants, studies investigating the neural mechanisms of empathy in adults have shown that the temporoparietal junction, an area also involved in the multisensory processing of body-related information and the phenomenological and cognitive aspects of self (Blanke \& Arzy, 2005), is also activated during the perception of pain in others (Jackson, Rainville, \& Decety, 2006). It seems thus that aspects of bodily self are related to affect sharing. Mature sense of self is crucial for empathic responses, as it allows the observer to go beyond affect sharing, appraise the other's emotional state in relation to oneself and engage in intersubjective exchanges (Decety \& Jackson, 2004). This further motivates investigation of these relations in infancy, when important aspects of self begin to develop.

It is also crucial that the initial affect sharing reaction to another's distress is modulated to an adaptive level through the use of various regulatory strategies that lead to its inhibition, activation or 
graded modulation. In children, for example, reduced emotion regulation abilities are related to increased arousal to an infant cry (Fabes et al., 1994).

Significant developments in emotion regulation take place during infancy, with younger infants using more primitive self-soothing strategies (e.g., digit or hand sucking) (Derryberry \& Rothbart, 1984; Hornick \& Gunnar, 1987), while withdrawal and escaping behaviors characterize more 3- to 6month-old infants (Shapiro, Fagen, Prigot, Carroll, \& Shalan, 1998). Also, attention based strategies become more frequent during the second half of the first year (Shapiro et al., 1998), when object distraction becomes more involved in regulating emotions (Braungart-Rieker \& Stifter, 1996; Mangelsdorf, Shapiro, \& Marzolf, 1995; Shapiro et al., 1998). This is probably due to development of endogenous attention, with older 7-month-olds being more reliably efficient to shift attention than the 3- or 4-month-olds (Colombo, Mitchell, \& Horowitz, 1988), while very young infants tend to have difficulties in disengaging attention, especially in stimuli competing situations (Hood, Willen, \& Driver, 1998). Fearfulness, as an index of inhibition of approach, increases as well (Carranza, PerezLopez, Gonzalez, \& Martinez-Fuentes, 2000; Gartstein \& Rothbart, 2003), being relevant for regulating the affective arousal (Grolnick, Cosgrove, \& Bridges, 1996), although mainly by withdrawal and disengagement from a distressful or challenging situation (Liew et al., in press).

The early emotional resonance responses seem to be regulated. In Haviland and Lelwica's study (1987), only half of the infants reacted with intense distress as evidenced by uncomforted crying to their mother's persistent angry face and voice. It seems thus that the rest of them, who showed less intense distress, were employing some regulatory strategies. But, what exactly are those emotion regulation strategies that relate to infant's emotional resonance is still a matter of further investigation.

The goal of this paper is to investigate possible concurrent relations between infant emotional resonance and the emerging abilities for regulation and self-other differentiation. Infants' emotional reactions to the cry of another infant have been systematically used in previous studies as a sign of 
emotional resonance in both very young infants and older children (e.g., Dondi et al., 1999; Eisenberg, McCreath, \& Ahn, 1988; Simner, 1971). In the current study we aimed to investigate the individual differences for these particular reactions in 3-, 6-, and 9-month-old infants.

With respect to emotion regulation, we have chosen to analyze both infants' regulatory behaviors triggered by the perception of the cry sound, and parents' report of their babies' daily use of regulatory strategies. We have particularly focused on those aspects of emotion regulation that are specific for this age interval: comforting (i.e., thumb sucking/mouthing) and escape behaviors, as well as those temperamental elements that index regulatory strategies (e.g., attention based). We predict less emotional resonance when self-soothing behaviors are used, especially in younger infants, while for older age groups we would expect that infants with higher scores on temperamental dimensions that index attentional strategies will manifest less affect sharing reactions in response to another infant cry sound.

For self-other differentiation, we aim to analyze if the emergence of an implicit intermodal body schema is related to infants' emotional resonance. Previous studies have successfully employed visual preference paradigms to show that 7- to 9-month-old infants discriminate between their own body and that of others based on intermodal matching of sensorial information (Schmuckler \& Fairhall, 2001; Zmyj et al., 2009). Older, but not younger infants (2-month-old), prefer visual exploration of novel stimuli (Wetherford \& Cohen, 1973), and the underlying attentional processes also seem to be consistently present up to the age of 8-months (Colombo, Shaddy, Anderson, Gibson, Blaga, \& Kannass, 2010). Visual preference for the image of another body is therefore regarded as an index of self-other discrimination. In our study, we expect that infants with better abilities to differentiate self from other as reflected in longer looking duration towards the video image of another infant body will also manifest reduced personal distress in response to the observed negative affect. 
Affect Sharing in Infancy

\section{Method}

\section{Participants}

The final sample consisted of: 34 3-month-old infants (16 males, mean age: 96.23 days); 44 6-monthold infants (17 males, mean age: 182.47 days); and 44 9-month-old infants (18 males, mean age: 271.76 days). Additional 9 3-month-olds, 3 6-month-olds, and 4 9-month-olds responded to the invitation to participate but were not included because they became distressed shortly before the beginning of the procedure or when seated in the infant chair. Some infants completed only part of the procedure or parents did not return the questionnaire. In order to retain as much data as possible, subjects with only one set of data where included in the analysis for that task. All subjects were living in a mid-sized city in Europe. Infants were rewarded with a small toy for their participation, and, if necessary, parents received payment for car parking.

\section{Procedures and Measures}

Infants were assessed with two tasks in laboratory settings. At home, parents completed a questionnaire about their infant temperamental characteristics. The order of the laboratory tasks was the same for all participants: the self-other differentiation task first, followed after a ten minutes break by the affect sharing task. This order was determined by the nature of the affect sharing task, which is expected to induce negative emotional reactivity (e.g., Haviland \& Lelwica, 1987). In order for the response to self-other differentiation task not to be influenced by the potential negative affect, this task was always first.

1. The emotional resonance task. To measure the affect sharing responses, infants were presented with the cry sound of a peer. The stimulus was represented by the sound of a 3-month-old male infant crying, recorded during a blood sampling procedure, in a nearby hospital unit. The blood sampling triggered a cry from first to last vocalization of 199 s. During the procedure, this cry sound 
was played continuously twice, for a maximum duration of $360 \mathrm{~s}$. The task consisted of a baseline and a test episode as per previous work in this area (Dondi et al., 1999; Field et al., 2007). During the $60 \mathrm{~s}$ baseline episode, in the absence of any auditory or visual stimulation, the infant's behavior was recorded. The test episode consisted of the presentation of the cry stimulus, and varied in duration as follows: $300 \mathrm{~s}$ for those infants who did not manifest cry vocalizations during this interval; maximum $360 \mathrm{~s}$ for those participants who started crying after the first $290 \mathrm{~s}$ from the stimulus onset. If the infant started to cry, a maximum of $30 \mathrm{~s}$ continuous cry was allowed until the parent was requested to start soothing him/her.

During the entire procedure, the infant was seated in an infant chair (reclined $65^{\circ}$ ). One camera $(\sim 100 \mathrm{~cm}$ in front of the child) recorded the infant behavior, and a speaker $(\sim 200 \mathrm{~cm}$ away from the infant, hidden by a dark curtain) played the stimulus. The parent sat approximately $100 \mathrm{~cm}$ away to the infant's left, and the experimenter sat behind the camera, partially occluded by it.

Infants' emotional resonance responses were coded in terms of different dimensions of facial expressivity and vocal reactions that match the perceived crying. Intensity of distress vocalizations, latency to signs of distress, facial expression patterns characteristic to anger and sadness are all considered to be parameters of emotional reactivity (Kochanska, Coy, Tjebkes, \& Husarek, 1998; Rothbart, Ellis, \& Posner, 2004) and so we reasoned they will be good indicators of affect sharing. The recordings were divided in 10 seconds units. For reliability, a second coder analyzed $20 \%$ of the data. Intraclass correlation based on absolute agreement is presented in parentheses for each dimension.

The following behaviors were coded as present or absent for each unit. Facial expressivity criteria derived from AFFEX were used for coding expressions of anger (.976) and sadness (.875) as described by Goldsmith and Rothbart (1999). For either facial expression to be coded, specific movements in at least two of the following face regions should be displayed: forehead/brows regions; eyes/nose/cheek regions; mouth/lips/chin regions. Facial movements that are specific for anger and 
sadness can appear simultaneously, leading to mixed facial expressions (Sullivan \& Lewis, 2003). If this was the case, expressions of both anger and sadness were coded as present for the same 10-second unit. Also, in cases where a facial expression started in one unit and continued for more than one unit, it was coded as present for each of them.

Cry vocal reactions were defined as audible, intermittent vocalization of distress (Simner, 1971). We scored the presence of the cry vocalizations (.911) and the intensity of the cry (.958) for each unit. The intensity was rated on a scale from 1 to 5 (1 - mild protest verbalization that may be difficult to identify as negative, 5 - full intensity cry/scream (Goldsmith \& Rothbart, 1999). Where a cry was elicited in one unit and lasted for more than one unit, the cry was scored as present for each of them, and the intensity was rated separately for each unit. The latency to the onset of crying (.960) was recorded as the number of units from the beginning of stimulus presentation to the onset of the first bout of cry. We coded this dimension only in the test phase, where we could establish with precision the beginning of the stimulation.

2. The self-other discrimination task. We used the task described by Bahrick \& Watson (1985), indexing aspects of the implicit intermodal body schema. The participant was seated in an infant high chair, adjusted so that infant's view of his/her own legs was occluded. In front of the participant, approximately $100 \mathrm{~cm}$ away, 2 TV monitors were placed at the same level as the head and torso of the infant. These were set side by side, $15 \mathrm{~cm}$ away from each other and turned inward by an approximate $15^{\circ}$ angle. A dark curtain masked them, so that only the screens were visible to the participant. A camera situated above the infant, $165 \mathrm{~cm}$ high, recorded on-line the subject's own legs movements. This video recording represented the self stimulus and it was displayed on-line on one monitor. Prior to the session, the leg movements of another infant of the same age with the participant (either 3-, 6- or 9month-old) were recorded in the same position/setting. This recording represented the other stimulus, had a length of approximately $120 \mathrm{~s}$, and it was displayed off-line on the other monitor (Figure 1). 
Both the participant in the self condition and the infant in the other condition were wearing identical white trousers in order to increase physical appearance similarity between conditions. The presentation of the stimuli on the two monitors was counterbalanced across participants.

\section{- Figure 1 -}

A camera recorded the participant's head and torso for off-line coding. Participant's gazing was coded in terms of duration of the total fixation toward each TV monitor. Preferential looking for either the self or the other stimulus was indicated by greater fixation towards the corresponding TV monitor (Dannemiller \& Freedland, 1991). Also, we coded the subject's response in term of self leg movement. Subjects who did not manifest leg movement during testing were eliminated from the analysis for this task, since disproportionate leg motion for one stimulus compared to the other would represent a confound for preferential looking analysis. A second coder analyzed $20 \%$ of the data for reliability, with intraclass correlation based on absolute agreement .969 .

3. Emotional regulation was measured as the infant's observed performances in a potentially distress inducing situation (i.e., the situation created by the emotional resonance task) and via parental reports.

Observed measures of infant emotion regulation - thumb-sucking and escaping behaviors have been previously reported as being successfully employed by infants for regulating emotional arousal in various distress provoking tasks (Goldsmith \& Rothbart, 1999; Weinberg \& Tronick, 1994). For thumb-sucking (.959), any sucking actions applied to hand or any other parts of the body that lasted more than 1 second were coded. For escaping behaviors (.753), we coded the presence or absence of any attempts to escape from the seat by mild turning away, back arching, twisting away, leaning away, and kicking. Both behaviors were coded as present or absent for every $10 \mathrm{~s}$ unit, and a score was 
computed consisting of the percentage of time it was present from the total amount of time of stimulus presentation.

Parental reports of infant's emotional regulation abilities were obtained using the Infant Behavior Questionnaire - Revised (IBQ-R) (Gartstein \& Rothbart, 2003). IBQ-R is a widely used measure that has been developed for assessing both reactivity and regulation dimensions of temperament. For the current study we used those subscales that are theoretically related to selfregulatory processes (Cronbach's alpha coefficients are reported in parentheses): Duration of Orienting ( $\alpha=.738$; attention to and/or interaction with a single object for extended periods of time), Falling Reactivity $(\alpha=.703$; rate of recovery from peak distress, excitement, or general arousal; ease of falling asleep), Fear ( $\alpha=.876$; startle or distress to sudden changes in stimulation, novel physical objects or social stimuli; inhibited approach to novelty), and Sadness ( $\alpha=.731$; lowered mood and activity related to personal suffering, physical state, object loss, or inability to perform a desired action; general low mood).

\section{Results}

The duration of the test phase varied for each participant, therefore for further analysis we computed the percentage of units each infant spent crying, manifesting facial expressions of anger and sadness.

Descriptive data for the affect sharing task for each age group are presented in Table 1. A twoway 2 (condition: baseline vs. test phase) x 3 (age: 3- vs. 6- vs. 9-month-old) mixed ANOVA, with repeated measures on the first variable (Greenhouse - Geisser correction for the violations of the assumptions of variance homogeneity) indicate that infants manifested significantly more cry vocalizations $(F(1,102)=126.465, p<.001)$, anger $(F(1,102)=110.749, p<.001)$, and sadness $(F(1$, 
$102)=97.00, p<.001)$ during the test phase compared to baseline. Also, the cry was more intense during the test phase $(F(1,102)=160.954, p<.001)$. We found significant age effects for the cry vocalizations $(F(2,102)=3.26, p<.05)$, with 6-month-olds crying more than the 3-month-olds (Mean difference $=9.94, p<.05)$. Also, 6-month-olds manifested more sadness $(F(2,102)=5.68, p<.05)$ than both 3- $($ Mean difference $=6.85, p<.05)$ and 9-month-olds (Mean difference $=5.56, p<.05)$. There was a marginally significant age effect for cry intensity $(F(2,102)=2.62, p=.07)$, with a tendency for 6-month-olds to cry more intensely than the 3-month-olds (Mean difference $=.46, p=$ .07). A one way ANOVA (age x latency) revealed significant age effects $(F(2,102)=4.181, p<.05)$ with 6- $($ Mean difference $=-6.90, p<.05)$ and 9-month-olds (Mean difference $=-7.17, p<.05)$ having a faster onset of cry vocalizations than the 3-month-old infants. There was no significant difference between the 6- and the 9-month-old infants $(p>.05)$. Independent t-tests suggest that boys and girls manifest similar levels of emotional resonance for each dimension included in the study $(p s>.10)$.

- Table 1 -

\section{Interrelations of observed measures of self-regulatory behaviors and emotional resonance measures}

Thirteen (40.63\%) 3-month-old infants manifested thumb sucking behavior while perceiving the cry of another infant in distress, while only 7 (20.59\%) of the 6-month-olds and $7(19.44 \%)$ of the 9-month-olds exhibited the same behavior. Jonckheere-Terpstra test suggests a significant trend of decreased use of thumb sucking from age 3- to 9-months (Std. J-T statistic $=-2.302, p<.05$ ), while infants from all age groups manifested similar levels of escaping behaviors (Std. J-T statistic $=-1.231$, $p>.05)$. 
Because the 3-month-old group significantly used more thumb-sucking, we further analyzed whether the presence of this behavior was successful in altering the emotional response to another infant pain cry. We split this age group by the presence of thumb sucking. Independent samples t-test shows that infants who used thumb-sucking manifested less vocal distress $(t(32)=2.19, p<.05)$, with a lower intensity $(t(32)=2.86, p<.05)$, and less sadness $(t(32)=3.29, p<.05)$. Also, marginally significant, when thumb sucking was used, infants tended to have a delayed onset of crying $(t(32)=-$ $1.919, p=.065$ ) (Figure 2). No significant differences were found for the percentage of time they manifested angry facial expressions $(t(32)=1.32, p=.195)$. For older infants, thumb-sucking did not relate significantly with measures of contagious crying $(p s>.05)$.

Scores for escape behavior did not relate significantly with any of contagious cry measures at the age of 3- or at the age of 9-months ( $p$ s > .05), while for the 6-month-olds it correlated significantly and positively only with facial expression of anger $(r(34)=.352, p=.041)$, suggesting that increased attempts to escape a situation where this is not possible, is actually associated with increased levels of anger.

We also explored the independence of these behaviors from negative affect, by looking at their patterns of relations with temperamental fear. Neither thumb-sucking or escape behaviors related significantly with fear for both $3-(r(25)=-.240, p=.249 ; r(25)=.265, p=.201)$ and 6-month-old infants $(r(23)=.228, p=.296 ; r(23)=.276, p=.203)$. For the 9-month-old there was a significant, but negative, relation between thumb-sucking and levels of fear $(r(29)=-.422, p=.022)$.

- Figure 2 - 


\section{Interrelations of temperamental characteristics and emotional resonance measures}

Pearson correlations (2-tailed significance) for contagious crying measures and temperamental dimensions are presented in Table 2. Duration of Orienting and Falling Reactivity related significantly and consistently across dimensions with contagious crying.

\section{- Table 2 -}

Six-month-old infants with higher scores for Duration of Orienting cried with lower intensity $(r(23)=-.49, p=.019)$ and expressed less anger $(r(23)=-.43, p=.043)$ in response to the cry sound. There was also a tendency for 6-month-olds with higher scores on this subscale to manifest fewer cry vocalizations $(r(23)=-.38, p=.071)$ and to have a longer latency to the first bout of cry $(r(23)=.40, p$ $=.062$ ), but did not reach significance.

Three-month-olds' Duration of orienting correlated significantly solely with the intensity of vocal distress $(r(25)=.42, p=.036)$ and marginally significant with cry vocalizations $(r(25)=.35, p=$ .090). Interestingly, the direction of the relation is positive, and significantly different than the ones for 6-month-olds (based on Fisher Z transformation, $p=.001$ and $p=.010$, respectively).

Falling Reactivity related negatively with 3-month-olds' emotional resonance measures. Higher abilities to recover from a state of distress were associated with less vocal distress $(r(25)=-.40, p=$ $.046)$, and with a longer delay of onset $(r(25)=.44, p=.030)$. Three-month-old infants high on falling reactivity also tended to express less sadness, although this trend was marginally significant $(r(25)=-$ $.35, p=.083)$.

Fear as an index of inhibition, was not found to relate significantly with the contagious cry measures for any of the age groups included in the study. 
Affect Sharing in Infancy

\section{Self-other discrimination}

For the self-other discrimination task, the total amount of time subjects spent gazing to both stimuli was computed. Based on this score, we obtained the percentage of time subjects gazed to either the self or the other stimuli.

- $\quad$ Figure 3 -

Discrimination between conditions, based on preferential looking, is indicated by a significantly greater proportion of gaze fixation time on the other condition (Dannemiller \& Freedland, 1991) (Figure 3). For each age group, significance related to chance for both the self and the other conditions were analyzed via two-tailed t-tests. Three-month-old and 6-month-old participants did not manifest a greater proportion of fixation toward the other stimulus when compared to chance $(50 \%)$ : $t(34)=.584, p>.05$ and $t(44)=.375, p>.05$, respectively. For the 9-month-olds, the mean proportion of fixation toward the noncontingent other stimulus was found to be greater than chance $(50 \%): t(44)=$ $8.59, p<.05$

Possible age and gender effects on fixation toward the other stimulus were explored by 3 x 2 ANOVA. Individual analyses suggest significant effects for age $(F(2,121)=10.213, p=.001)$, but not for gender $(F(1,121)=.350, p=.555)$. Also, there were no significant interactions between age and gender $(F(2,121)=.757, p=.471)$. Post-hoc Games-Howel tests for unequal variances show that 9month-olds manifested a significantly greater percentage of looking fixation for the other stimulus than both the 3-month-olds (mean difference $=18.931, p=.005)$ and the 6-month-olds (mean difference $=$ 20.567, $p=.001$ ). The 6-month-olds' percentage of looking toward the other stimulus did not differ significantly from that of the 3-month-old infants (mean difference $=-1.636, p=.962$ ). 
All participants who successfully completed both the emotional resonance task and self-other discrimination task were further included in the analysis. Simple linear correlations were performed for analyzing possible covariations between data sets (Table 3).
\end{abstract}

- Table 3 -

We found significant relations between self-other discrimination, as a percentage of looking fixation towards the non-contingent other, and the parameters of contagious crying with the 9-monthold sample, but not for younger ages. Those 9-month-old participants with preferential looking toward the other, also manifested fewer cry vocalizations $(r(35)=-.342, p<.05)$ and reduced anger $(r(35)=-$ $.366, p<.05)$ in response to the perception of another infant cry. Also, those 9-month-olds who gazed longer at the other condition tended towards a delayed first bout of $\operatorname{cry}(r(35)=.333, p=.051)$.

For the 6-month-old group there was a marginally significant relation. More specifically, those 6-month-olds looking longer towards the other stimulus also tended to express more sadness in response to the cry stimulus $(r(34)=.301, p=.083)$.

\title{
Discussion
}

The present paper aimed to explore the relation between emotional resonance responses triggered by the perception of another's distress and the abilities to self-regulate and to differentiate self from others in infants 3- to 9-months of age. We bring evidence that young infants use regulatory strategies for modulating the emotional resonance response to another infant cry, and that self-other differentiation is related to low personal distress.

Previous studies have explored the relation between inhibition, attentional mechanisms of self- 
regulation, and infants' emotional arousal provoked by another person's distress, and have shown that 4-month-old regulatory abilities significantly predict later empathic distress (12- and 24-months) (Ungerer et al., 1990; Young, Fox, \& Zahn-Waxler, 1999). For the present study, we used an experimental paradigm known to trigger affect sharing in infants. With a carefully selected auditory stimulus (the pain cry of a 3-months-old infant), we have shown that the observed individual variability in infants' emotional reactions is concurrently related with self-regulation.

Different regulatory strategies were employed by infants, according to their age group. Threemonth-olds used more thumb sucking and this behavior proved successful in down-regulating their emotional resonance responses, leading to a less intense vocal distress, which had also a longer latency. This is in agreement with previous studies that documented the efficiency of thumb-sucking in regulating emotional reactivity in younger infants (Campos, Campos, \& Barrett, 1989; Tronick, 1989). Our findings are consistent across different but related measures of the emotional response. Importantly, thumb-sucking was not found to be related at this age to infants' tendencies to respond with negative affect in everyday life situations. This further suggests that it is an independent index of regulation rather than a correlate of negative affect, as has been previously mentioned (Ungerer et al., 1990).

A similar pattern of findings was obtained for the temperamental regulatory dimension of falling reactivity. It refers to the rate of recovery from peak distress, excitement or general arousal, and reflects the infant's ability to regulate his/her own state (Gartstein \& Rothbart, 2003). We found that 3month-old's better abilities to regulate peak emotional reactions is associated with reduced contagious crying in response to another infant sound of distress. This temperamental dimension might not represent a specific regulatory strategy, but more likely points to the use of some regulatory strategies, other than thumb-sucking, specific to this age group. This is because we found no significant relation between them $(r=-.278, p>.05)$, although both were associated with decreased emotional resonance. 
Duration of orientation indexes attentional abilities as important regulatory processes (Emde \& Robinson, 1979; Rothbart, Ziaie, \& O'Boyle, 1992). We found that this ability was efficient in regulating infants' emotional reactions to another's distress, and this relation was consistently significant only for the 6-month-old group. This is in line with data showing that from 6- to 9-months of age, duration of orientation decreases significantly (Carranza et al., 2000), and that usually 6-montholds use more gaze aversion than both 12- and 18-month-old infants in a distressful social situation (Mangelsdorf et al., 1995). Similarly, Hay, Nash, and Pedersen (1981) have shown that 6-month-olds tend to become distressed by their peer's negative affect when there are fewer toys in the environment. In our current study we assessed infant's attention orientation abilities in everyday life contexts which limits our understanding of the particular way these strategies are used when affect sharing reactions arise. However, the combined data from these separate studies, suggest that most likely, 6-month-olds disengage attention from the distress of their peer and reorient towards a distracting stimulus. In contrast, three-month-olds with higher levels of duration of orientation manifested more intense vocal distress in response to the cry sound. One possible explanation is that very young infants' attention is more exogenously driven by the stimulus properties, while they are not yet fully efficient in disengaging attention (Hood et al., 1998; Johnson, Dziurawiec, Ellis, \& Morton, 1991). In our particular case, the high salience of the negative stimulus might retain 3-month-olds' concentration of attention, while their incipient abilities for attentional shifting may not be sufficient for reorienting to another distracting and comforting stimulus.

We did not find any relationships between self-regulatory abilities and contagious crying in 9month-olds. There are several possible explanations. First, this age group manifested similar levels of distress to the perception of another infant pain cry with the 6-month-old group, which suggests that they also employ some regulatory strategies. Since for older infants there is a tendency toward specialization of certain regulation strategies for specific situations and stimuli (Cicchetti, Ganiban, \& 
Barnett, 1991), and for specific emotions (Buss \& Goldsmith, 1998), they might not have been captured by the global measure based on parental report we used (IBQ-R). The observed measures of emotion-regulation (thumb-sucking and escape behavior) proved to be either specific for one age (i.e., thumb-sucking for 3-month-olds) or not associated with emotional reactivity (i.e., escaping behaviors). More refined assessments of regulation that include psychophysiological recordings in addition to parental report and observational measures (see for example Hastings, Rubin, \& DeRose, 2005) could be used in future research for an in-depth analysis of its relation with emotional resonance reactions. Second, the relation between emotional reactivity and regulation might follow a more complex pattern than simple one way and unmediated causality (Buss \& Goldsmith, 1998). This may be the case especially for older infants, where both emotional reactivity and regulation register an increase (Gartstein \& Rothbart, 2003), and start to influence each other in determining the child's reactions to emotion inducing situations (Eisenberg et al., 2000). This line of explanation is also consistent with our findings for the 6-months-olds, where, although there was a significant down-regulatory effect from attentional mechanisms, the levels of emotional reactivity triggered by the perception of another infant pain cry were on certain dimensions higher than those for 3-month-olds. Also, as the pattern of social interactions becomes increasingly complex towards the end of the first year of life, other factors, like the parenting style, may start playing a role in how emotionality and regulatory mechanisms are related to affect sharing and empathic behaviours (Hastings et al., 2005).

In general, the present study brings evidence for the relation between affect sharing and selfregulation abilities in infancy. Models of empathy (Decety \& Jackson, 2004; Eisenberg \& Fabes, 1990) stipulate that pure emotional contagion/sharing triggered by the perception of another distress must be controlled in order to afford emotions and behaviors that are prosocial in nature. Previous studies have shown that toddlers, preschoolers and school age children self-regulation is associated with reduced personal distress and increased prosocial behaviors (Fabes, Eisenberg, \& Eisenbud, 1993; Fabes et al., 
1994; Kochanska, Murray, \& Coy, 1997; Rothbart, Ahadi, \& Hershey, 1994; Zahn-Waxler, et al., 1983; Valiente et al., 2004; Young et al., 1999). Our results add to the existent body of research by showing that even infants regulate the vicariously induced emotional reactions.

One important aspect of empathy is the minimal awareness that the shared emotional reaction is triggered by the observed affective state of another person (Eisenberg, 2000; Hoffman, 2000; de Vignemont \& Singer, 2006). Our data suggests that already by the age of 9-months, there is a significant link between the developing sense of self and emotional resonance to another's distress. We found that 9-month-old infants, who manifest greater preference for perceiving another infant's body than their own, produce fewer cry vocalizations and fewer facial expression of anger in response to the cry of another infant. Also, they tended to have a longer latency to the onset of crying.

Self awareness is regarded as a top-down process that restricts the tendency to fully share the emotions of others (Decety \& Jackson, 2004), potentially explaining its positive relation with prosocial behavior (Zahn-Waxler et al., 1992) and its negative relation with affect sharing reactions like the emotional resonance in the present study. However, Zahn-Waxler et al. (1992) did not find a significant relationship between self-awareness and sympathetic concern. Several explanations may account for these findings. First, parental reports were used to assess toddlers' sympathetic concern. While prosocial behavior is easier to conceptualize and to observe, facial and vocal expressions of emotion can be easily missed or misinterpreted when not explicitly investigated. Second, the emotional reactions to the distress of another were assessed globally. We measured emotional resonance in infants 3- to 9-months of age by looking at different aspects of emotional expressivity (both facial and vocal). Although the relation with self-other awareness was consistent across some of these measures, it did not apply to all of them. Therefore, a more componential conceptualization of affective sharing response as a component of empathy is more informative than a global assessment, especially when investigating its relation with other processes. 
Another important aspect refers to how different dimensions of self development such as the sense of self as agent (either social or physical); the self as a set of intermodal integrated sensorial information about own body; the representations of self based on external features (either of the face or of the legs) relate with other components of empathy, and emotional sharing in particular, during infancy. This is also because little is known regarding the relation between these dimensions of self development as facets of the same concept. The present study, along with the studies of Zahn-Waxler et al. (1992) and Kärtner et al. (2004), show that both the sense of self as a set of intermodal integrated sensorial information about own body and the representation of self relate with empathic responses (emotional sharing and prosocial behavior).

We have shown that self-other awareness, as indexed by the manifested visual preference for the moving legs of another, is related to emotional sharing reactions in 9-month-old infants. This may be further involved in the elaboration of prosocial behavior as suggested by studies with older children.

Since self-other awareness related to reduced affect sharing only for the oldest infants in our study, while even 2-month-olds show some signs of discrimination between one's own body and others (Rochat \& Striano, 1999a), it suggests that a certain level of maturity within this skill is required. It is difficult to infer how the findings in our study could predict further relations between affect sharing and a sense of self, as the relation between early forms of self-awareness that rely mostly on intermodal perception of one's own body, and the later more representational ones, is still only marginally understood (Nielsen, Suddendorf, \& Slaughter, 2006). There seems, however, to be an agreement that increased self-awareness is related with affect sharing modulation. Importantly affect sharing experiences might influence the development of sense of self, as it has been proposed that it is within interpersonal exchanges that the infant acquires information about both self and the others (Tomasello, 1995). It could be therefore speculated that, by resonating to other's affect, infants learn about themselves as emotional agents. 
The current cross-sectional design limits our interpretation regarding how different dimensions of infants' emotional resonance to another distress relate to the fully developed empathy. For example, Zahn-Waxler et al. (1992) argued that sadness in response to another's distress is a sign of empathy, while anger is more a sign of self-distress. Our study shows that both crying and sadness relate to regulation and self-other awareness in a way consistent with their interpretation as precursors of empathy. However, the current data does not allow for such a rich interpretation. One possible solution could be to follow the same infants at different ages and investigate the predictive value of different dimensions of emotional resonance for later more mature forms of empathy.

Impairments in empathic abilities are specific for a series of mental disorders, including autistic spectrum disorders (Decety \& Moriguchi, 2007). By toddlerhood, atypical patterns of responses to another's distress are already evident in autistic individuals (Charman, Swettenham, Baron-Cohen, Cox, Baird, \& Drew, 1997). A better understanding of the mechanisms underlying empathy development in infancy could prove crucial for early detection of autistic symptoms, and facilitate the application of specifically designed intervention programs (Roth-Hanania, Busch-Rossnagel, \& Higgins-D’Alessandro, 2000).

Affect sharing, along with self-other awareness and regulation are processes particularly important for early development of empathy. We found important evidence that affective resonance to another's distress is modulated by emotion regulation mechanisms and self-awareness at different age points in infancy. Further studies that address the predictive nature of these early abilities to the later empathic responses and prosocial behaviors will be particularly important for validating them as early precursors of empathy development. 
Affect Sharing in Infancy

\section{References}

Bahrick, L. E., \& Watson, J. S. (1985). Detection of intermodal proprioceptive-visual contingency as a potential basis of self-perception in infancy. Developmental Psychology, 21(6), 963-973.

Blanke, O., \& Arzy, S. (2005). The out-of-body experience: disturbed self-processing at the temporoparietal junction. Neuroscientist, 11(1), 16-24.

Braungart-Rieker, J. M., \& Stifter, C. A. (1996). Infants' responses to frustrating situations: continuity and change in reactivity and regulation. Child Development, 67(4), 1767-1779.

Roth-Hanania, R., Busch-Rossnagel, N., \& Higgins-D’Alessandro, A. (2000). Development of self and empathy in early infancy: implications for atypical development. Infant and Young Children, 13(1), 1-14.

Buss, K. A., \& Goldsmith, H. H. (1998). Fear and anger regulation in infancy: Effects on the temporal dynamic of affective expression. Child Development, 69(2), 359-374.

Calkins, S. D., \& Hill, A. (2007). The emergence of emotion regulation: Biological and behavioral transactions in early development. In J. Gross \& R. Thompson (Eds.), The Handbook of Emotion Regulation (pp. 229-248). New York, NY: Guilford Press.

Campos, J., Campos, R., \& Barrett, K. (1989). Emergent themes in the study of emotional development and emotion regulation. Developmental Psychology, 25(3), 394-402.

Carranza, J. A., Perez-Lopez, J., Gonzalez, C., \& Martinez-Fuentes, M. T. (2000). A longitudinal study of temperament in infancy: Stability and convergence of measures. European Journal of Personality, 14(1), 21-37.

Charman, T., Swettenham, J., Baron-Cohen, S., Cox, A., Baird, G., \& Drew, A. (1997). Infants with autism: an investigation of empathy, pretend play, joint attention, and imitation. Developmental Psychology, 33(5), 781-789.

Cicchetti, D., Ganiban, J., \& Barnett, D. (1991). Contributions from the study of high-risk populations to 
understanding the development of emotion regulation. In J. Garber \& K. Dodge (Eds.), The Development of emotion regulation (pp. 15-48). New York: Cambridge University Press.

Colombo, J., Mitchell, D. W., \& Horowitz, F. D. (1988). Infant visual attention in the pairedcomparison paradigm: test-retest and attention-performance relations. Child Development, 59, 1198-1210.

Colombo, J., Shaddy, D. J., Anderson, C. J., Gibson, L. J., Blaga, M. O., \& Kannass, K. N. (2010). What habituates in infant visual habituation? A psychophysiological analysis. Infancy, 15(2), 107-124.

Dannemiller, J. L., \& Freedland, R. (1991). Detection of relative motion by human infants. Developmental Psychology, 27(1), 67-78.

DeCasper, A. J., \& Fifer, W. P. (1980). Of human bonding: Newborns prefer their mothers' voices. Science, 280(6), 1174-1176.

Decety, J., \& Jackson, P. L. (2004). The functional architecture of human empathy. Behavioral and Neuroscience Reviews, 3(2), 71-100.

Decety, J., \& Moriguchi, Y. (2007). The empathic brain and its dysfunction in psychiatric populations: implications for intervention across different clinical conditions. BioPsychoSocial Medicine, 1:22. doi:10.1.1186/1751-0759-1-22.

Derryberry, D., \& Rothbart, M. K. (1984). Emotion, attention, and temperament. In C. E. Izard, J. Kagan, \& R. B. Zajonc (Eds.), Emotions, cognition, and behavior (pp. 132-166). Cambridge: University Press.

De Vignemont, F., \& Singer, T. (2006). The empathic brain: how, when and why? Trends in Cognitive Sciences, $10(10), 435-441$.

de Waal, F. (2006). Morally evolved: primates social instincts, human morality, and the rise and fall of "Veneer Theory". In S. Macedo \& J. Ober (Eds.) "Primates and Philosophers. How Morality 
Evolved” (pp. 1-83). NJ: Princeton University Press.

Dondi, M., Simion, F., \& Caltran, G. (1999). Can newborns discriminate between their own cry and the cry of another newborn infant? Developmental Psychology, 35(2), 418-426.

Eisenberg, N. (2000). Emotion, regulation, and moral development. Annual Review of Psychology, 51, 665-697.

Eisenberg, N., \& Fabes, R. A. (1990). Empathy: Conceptualization, measurement, and relation to prosocial behavior. Motivation and Emotion, 14(1), 131-149.

Eisenberg, N., Guthrie, I. K., Murphy, B. C., Shepard, S. A., Cumberland, A., \& Carlo, G. (1999). Consistency and development of prosocial dispositions: a longitudinal study. Child Development, 70(6), 1360-1372.

Eisenberg, N., Guthrie, I. K., Fabes, R. A., Shepard, S., Losoya, S., Murphy, B. C., ... Reiser, M. (2000). Prediction of elementary school children's externalizing problem behaviors from attentional and behavioral regulation and negative emotionality. Child Development, 71(5), 1367-1382.

Eisenberg, N., McCreath, H., \& Ahn, R. (1988). Vicarious emotional responsiveness and prosocial behavior - their interrelations in young children. Personality and Social Psychology Bulletin, 14(2), 298-311.

Eisenberg, N., Shea, C. L., Carlo, G., \& Knight, G. P. (1991). Empathy-related responding and cognition: A "chicken and the egg" dilemma. In W. M. Kutines \& J. L. Gerwirtz (Eds.), Handbook of moral behavior and development: Research (Vol. 2, pp. 63 - 88). Hillsdale, NJ: Lawrence Erlbaum Associates.

Emde, R. N., \& Robinson, J. (1979). The first two months: Recent research in developmental psychobiology and the changing view of the newborn. In J. Call, J. Noshpitz, R. Cohen, \& I. Berlin (Eds.), Basic handbook of child psychiatry (Vol. 1, pp. 72-105). New York: Basic 
Books.

Fabes, R. A., Eisenberg, N., \& Eisenbud, L. (1993). Behavioral and physiological correlates of children's reactions to others in distress. Developmental Psychology, 29(4), 655-663.

Fabes, R. A., Eisenberg, N., Karbon, M., Troyer, D., \& Switzer, G. (1994). The relations of children's emotion regulation to their vicarious emotional responses and comforting behaviors. Child Development, 65(6), 1678-1693.

Field, T., Diego, M., Hernandez-Reif, M., \& Fernandez, M. (2007). Depressed mothers' newborns show less discrimination of other newborns' cry sounds. Infant Behavior and Development, $30(3), 431-435$.

Gartstein, M. A., \& Rothbart, M. K. (2003). Studying infant temperament via a revision of the Infant Behavior Questionnaire. Journal of Infant Behavior and Development, 26(1), 64-86.

Geangu, E., Benga, O., Stahl, D., \& Striano, T. (2010). Contagious crying beyond the first days of life. Infant Behavior and Development, 33(3), 279-288.

Gergely, G. (2002). The development of understanding self and agency. In U. Goswami (Ed.), Blackwell Handbook of Childhood Cognitive Development, (pp. 26-46). Oxford: Blackwell.

Goldsmith, H. H., \& Rothbart, M. K. (1999). The Laboratory Temperament Assessment Battery (Prelocomotor Version, Edition 3.1). Madison, WI: University of Wisconsin-Madison.

Grolnick, W. S., Cosgrove, T., \& Bridges, L. J. (1996). Age-graded change in initiation of positive affect. Infant Behavior and Development, 19(1), 153-157.

Hastings, P. D., Rubin, K. H., \& DeRose, L. (2005). Links among gender, inhibition, and parental socialization in the development of prosocial behavior. Merrill-Palmer Quaterly, 51(4), 467493.

Haviland, J. M., \& Lelwica, M. (1987). The induced affect response: 10-week-old infants' responses to three emotion expressions. Developmental Psychology, 23(1), 97-104. 
Affect Sharing in Infancy

Hay, D. F., Nash, A., \& Pedersen, J. (1981). Responses of six-month-olds to the distress of their peers. Child Development, 52, 1071-1075.

Hoffman, M. L. (2000). Empathy and Moral Development. Implications for Caring and Justice. Cambridge University Press.

Hood, B. M., Willen, J. D., \& Driver, J. (1998). Adult's eyes trigger shifts of visual attention in human infants. Psychological Science, 9(2), 131-134.

Jackson, P. L., Rainville, P., \& Decety, J. (2006). To what extent do we share the pain of others? Insight from the neural bases of pain empathy. Pain, 125(1-2), 5-9.

Kärtner, J., Keller, H., Kleis, A., \& Lamm, B. (2004, August). Influences of contingent responsiveness on the development of self-recognition and empathy with 18 months. Paper presented at the 28th International Congress of Psychology (ICP), Beijing, China.

Knafo, A., Zahn-Waxler, C., Van Hulle, C., Robinson, J. L., \& Rhee, S. H. (2008). The developmental origins of a disposition toward empathy: genetic and environmental contributions. Emotion, $8(6), 737-52$.

Kochanska, G., Coy, K. C., Tjebkes, T. L., \& Husarek, S. J. (1998). Individual differences in emotionality in infancy. Child Development, 69(2), 375-390.

Kochanska, G., Murray, K., \& Coy, K. C. (1997). Inhibitory control as a contributor to conscience in childhood: From toddler to early school age. Child Development, 68(2), 263-277.

Kopp, C. B. (1982). Antecedents of self-regulation: a developmental perspective. Developmental Psychology, 18(2), 199-214.

Liew, J. Eisenberg, N., Spinrad, T. L., Eggum, N. D., Haugen, R. G., Kupfer, A., ... Baham, M. E. (in press). Physiological regulation and fearfulness as predictors of young children's empathyrelated reactions. Social Development. Retrieved from http://www3.interscience.wiley.com/cgibin/fulltext/123325782/PDFSTART 
Mangelsdorf, S., Shapiro, J., \& Marzolf, D. (1995). Developmental and temperamental differences in emotion regulation in infancy. Child Development, 66(6), 1817-1828.

Martin, G., \& Clark, R. (1982). Distress crying in neonates: Species and peer specificity. Developmental Psychology, 18(1), 3-9.

Nielsen, M., Suddendorf, T., \& Slaughter, V. (2006). Mirror self-recognition beyond the face. Child Development, 77(1), 176-185.

Rochat, P. (1998). Self-perception and action in infancy. Experimental Brain Research, 123, 102-109.

Rochat, P., \& Hespos, S. J. (1997). Differential rooting responses by neonates: evidence for an early sense of self. Early Development \& Parenting, 6(3-4), 105-112.

Rochat, P., \& Morgan, R. (1995). Spatial determinants in the perception of self-produced leg movements in 3- to 5-month-old infants. Developmental Psychology, 31(4), 626-636.

Rochat, P., \& Striano, T. (1999a). Social cognitive development in the first year. In P. Rochat (Ed.), Early social cognition (pp. 1-34). Hillsdale, NJ: Lawrence Erlbaum Associates.

Rochat, P., \& Striano, T. (1999b). Emerging self-exploration by 2-month-old infants. Developmental Science, 2(2), 206-218.

Rochat, P., \& Striano, T. (2000). Perceived self in infancy. Infant Behavior \& Development, 23(3-4), 513-530.

Rochat, P., \& Striano, T. (2002). Who's in the mirror? Self-other discrimination in specular images by four- and nine-month-olds infants. Child Development, 73(1), 35-46.

Roth-Hanania, R., Busch-Rossnagel, N. A., \& Higgins-D’Alessandro, A. (2000). Development of self and empathy in early infancy: implications for atypical development. Infants and Young Children, 13(1), 1-14.

Rothbart, M. K., Ahadi, S. A., \& Hershey, K. L. (1994). Temperament and social behavior in childhood. Merrill-Palmer Quarterly, 40, 21-39. 
Affect Sharing in Infancy

Rothbart, M. K., Ellis, L. K., \& Posner, M. I. (2004). Temperament and self-regulation. In R. F. Baumeister \& K. D. Vohs (Eds.), Handbook of self-regulation: research, theory, and applications (pp. 357-370). New-York: Guilford Press.

Rothbart, M., Ziaie, H., \& O’Boyle, C. (1992). Self-regulation and emotion in infancy. In N. Eisenberg \& R. Fabes (Eds.), Emotion and its regulation in early development (pp. 7-23). San Francisco: Jossey-Bass.

Sagi, A., \& Hoffman, M. L. (1976). Empathic distress in the newborn. Developmental Psychology, 12(2), 175-176.

Schmuckler, M. A., \& Fairhall, J. L. (2001). Visual-proprioceptive intermodal perception using pointlight displays. Child Development, 72(4), 949-962.

Simner, M. L. (1971). Newborn's response to the cry of another infant. Developmental Psychology, 5(1), 136-150.

Shapiro, B., Fagen, J., Prigot, J., Carroll, M., \& Shalan, J. (1998). Infants' emotional and regulatory behaviors in response to violations of expectancies. Infant Behavior and Development, 21(2), 299-313.

Sullivan, M. W., \& Lewis, M. (2003). Emotional expressions of young infants and children - a practitioner's primer. Infants and Young Children, 16(2), 120-142.

Tomasello, M. (1995). Joint attention as social cognition. In C. Moore \& P. Dunham (Eds.) Joint attention: its origins and role in development (pp. 103-130). Erlbaum, Hillsdale NJ.

Valiente, C., Eisenberg, N., Fabes, R. A., Shepard, S. A., Cumberland, A., \& Losoya, S. H. (2004). Prediction of children's empathy-related responding to their effortful control and parents' expressivity. Developmental Psychology, 40(6), 911-926.

Ungerer, J. A., Dolby, R., Waters, B., Barnett, B., Kelk, N., \& Lewin, V. (1990). The early development of empathy: self-regulation and individual differences in the first year. Motivation 
and Emotion, 14(2), 93-106.

Zmyj, N., Hauf, P., \& Striano, T. (2009). Discrimination between real-time and delayed visual feedback of self-performed leg movements in the first year of life. Cognition, Brain, Behavior. An Interdisciplinary Journal, 13(4), 479-489

Zahn-Waxler, C., Friedman, S. L., \& Cummings, E. M. (1983). Children's emotions and behaviors in response to infants' cries. Child Development, 54(6), 1522-1528.

Zahn-Waxler, C., Radke-Yarrow, M., Wagner, E., \& Chapman, M. (1992). Development of concern for others. Developmental Psychology, 28(1), 126-136.

Young, S. K., Fox, N. A., \& Zahn-Waxler, C. (1999). The relations between temperament and empathy in 2-year-olds. Developmental Psychology, 35(5), 1189-1197.

Weinberg, K. M., \& Tronick, E. Z. (1994). Beyond the face: an empirical study of infant affective configurations of facial, vocal, gestural, and regulatory behaviors. Child Development, 65(5), 1503-1515.

Wetherford, M. J., \& Cohen, L. B. (1973). Developmental changes in infant visual preferences for novelty and familiarity. Child Development, 44, 416-424. 
Tables

Table 1

Means, standard deviations, and percentages of emotional resonance responses to the perception of the cry sound for each age group.

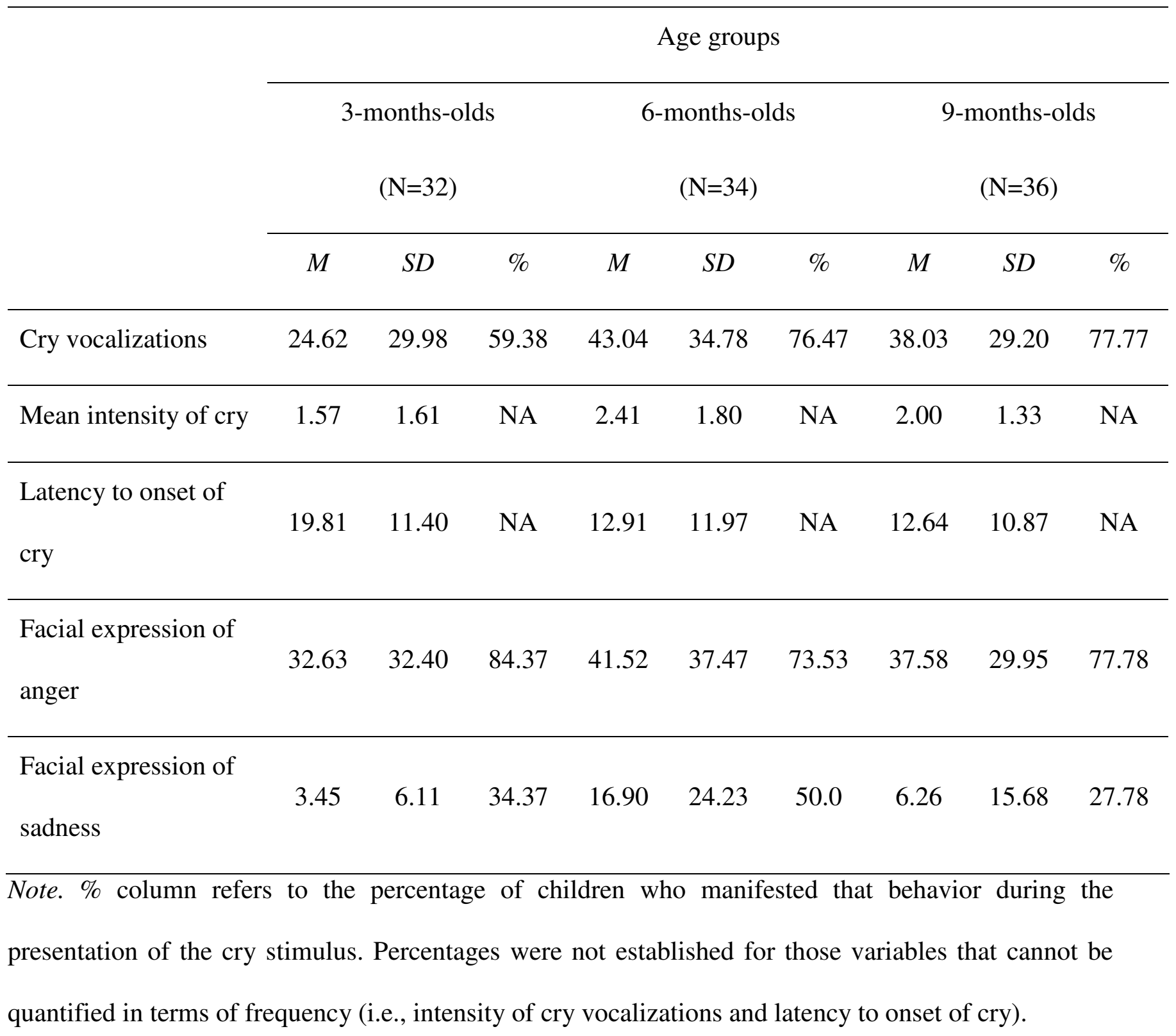


Table 2

Intercorelations of measures of emotional resonance and temperament by age group

\begin{tabular}{|c|c|c|c|c|c|c|c|c|c|c|c|c|c|c|c|}
\hline \multirow[b]{4}{*}{ IBQ-R Scale } & \multicolumn{15}{|c|}{ Emotional resonance measures } \\
\hline & \multicolumn{15}{|c|}{ Age groups } \\
\hline & \multicolumn{5}{|c|}{3 month-old $(N=25)$} & \multicolumn{5}{|c|}{6 month-old $(N=23)$} & \multicolumn{5}{|c|}{9 month-old $(N=29)$} \\
\hline & 1 & 2 & 3 & 4 & 5 & 1 & 2 & 3 & 4 & 5 & 1 & 2 & 3 & 4 & 5 \\
\hline Duration of orienting & $.42 *$ & .35 & -.26 & .06 & .13 & $-.49 *$ & $-.38^{\dagger}$ & $.40^{\dagger}$ & -.18 & $-.43 *$ & -.10 & -.10 & -.07 & .30 & -.07 \\
\hline Fear & $-.37^{\dagger}$ & -.12 & .15 & -.14 & -.24 & -.03 & .04 & -.02 & .03 & -.08 & .13 & .05 & -.06 & .16 & .13 \\
\hline Falling reactivity & -.26 & $-.40 *$ & $.44^{*}$ & $-.35^{\dagger}$ & $-.60 * *$ & .11 & .31 & -.33 & -.07 & .25 & .33 & .24 & -.30 & -.18 & .26 \\
\hline Sadness & .20 & $.35^{\dagger}$ & $-.43 *$ & -.01 & .29 & -.20 & -.24 & .18 & .08 & -.19 & $.45^{*}$ & .23 & $-.39 *$ & .23 & .18 \\
\hline
\end{tabular}

Note. 1 - Mean intensity of cry; 2 - Cry vocalizations; 3 - Latency to onset of cry; 4 - Facial expression of sadness; 5 - Facial expression of anger

${ }^{\dagger} p<.10 ; * p<.05 ; * * p<.01$ 
Affect Sharing in Infancy

Table 3

Correlations between time looking towards "other" stimulus and parameters of contagious crying for all age groups

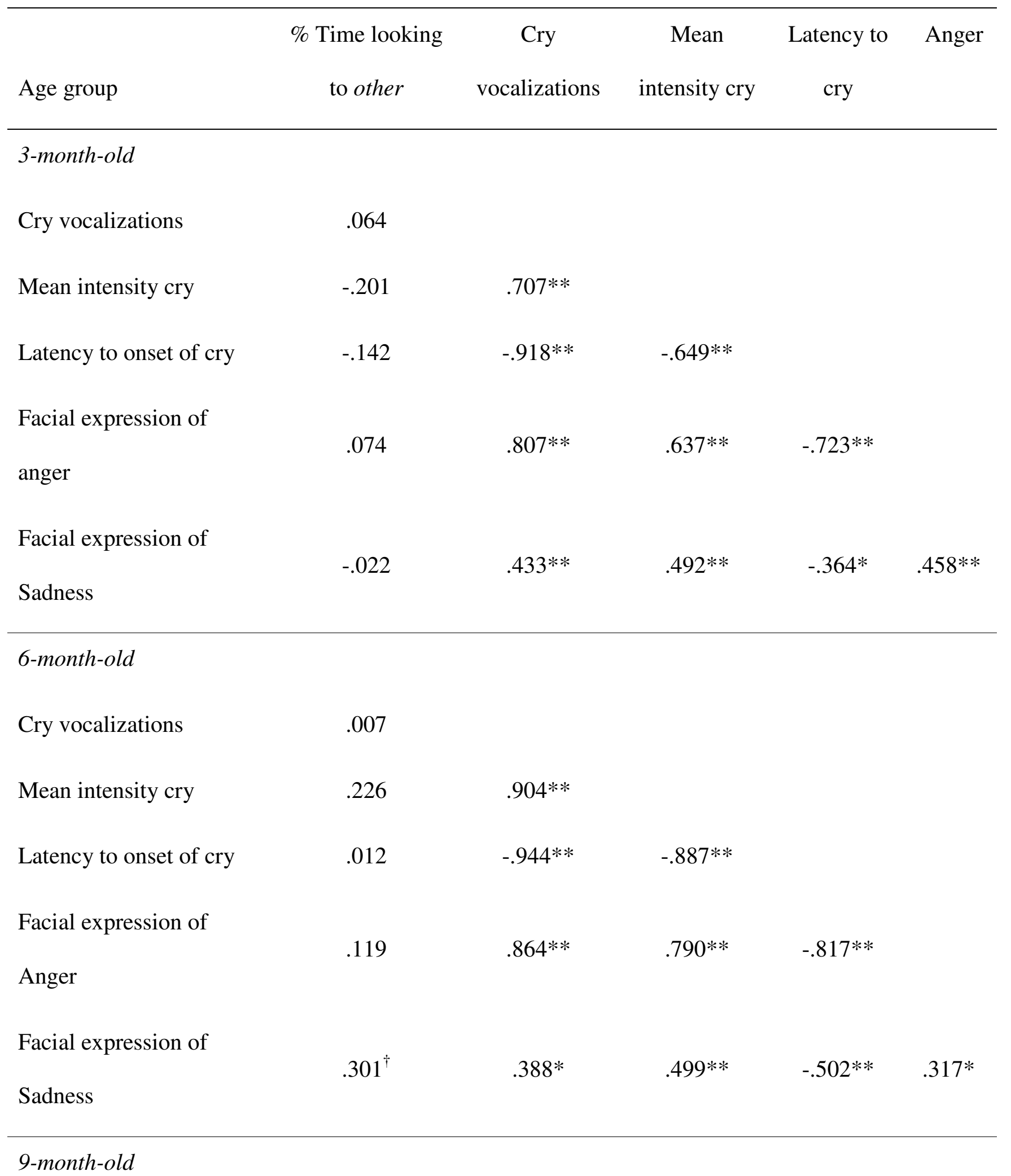


Affect Sharing in Infancy

Cry vocalizations

$-.342 *$

Mean intensity cry $-.217$

Latency to onset of cry

$.333^{\dagger}$

$-.366^{*}$

$.966 * *$

$.819 * *$ $-.839 * *$

Anger

Facial expression of

Sadness 
Figure captions

Figure 1. Example of video output used for offline coding of preferential looking for self or other stimuli (presented from the subject's view), with a 9-month-old male subject.

Figure 2. Emotional resonance responses (with SEs) during the presentation of the cry sound for 3month-old infants based on the presence or absence of thumb-sucking behavior.

Figure 3. Mean percentage looking time (with SEs) towards "self" stimulus and "other" stimulus according to age groups. 
Affect Sharing in Infancy

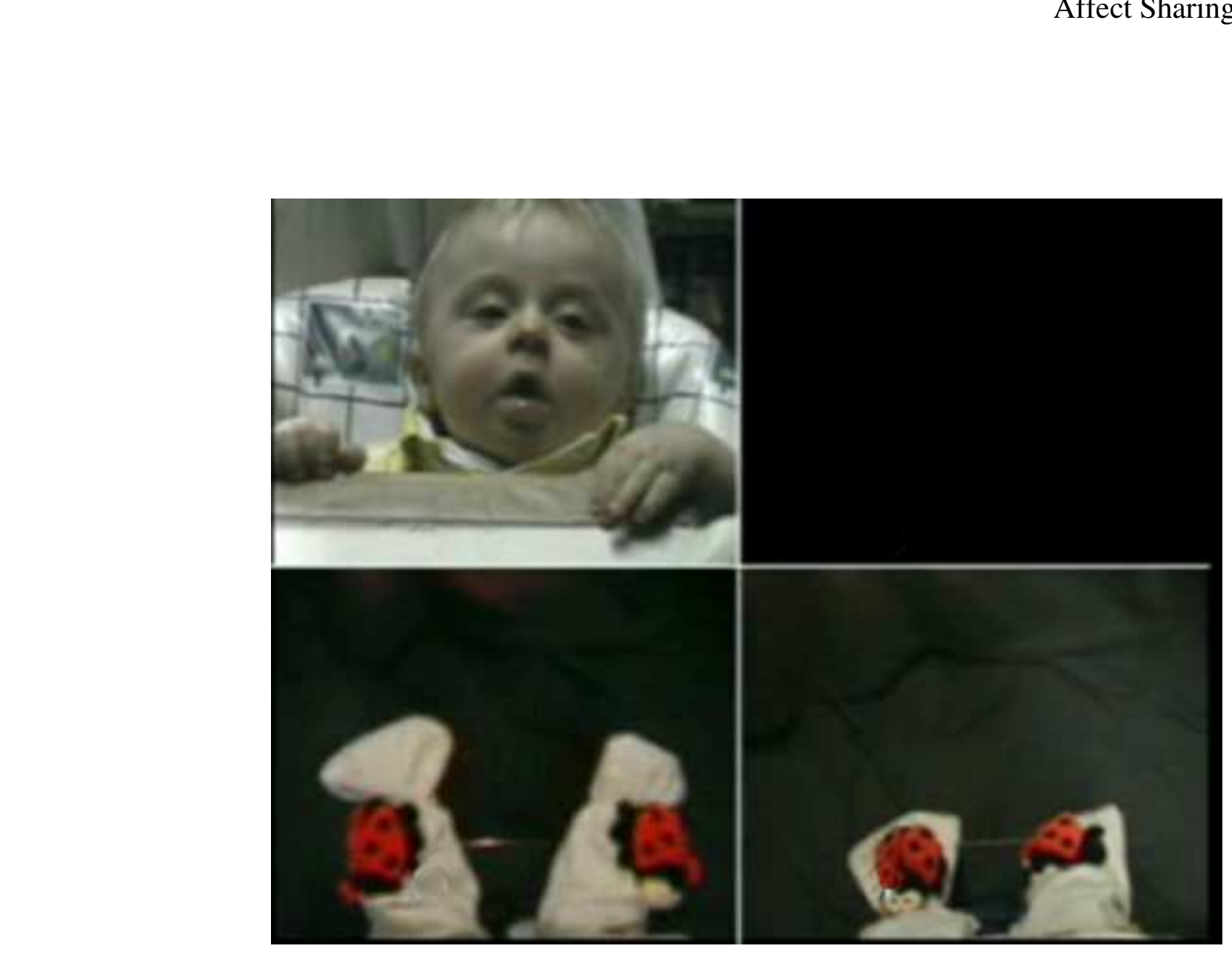

Social Development

\section{Page 37 of 39}

1

3

4

5

6

9

10

11

12

13

14
15

16

17

18

19

20

21

22

23

24

25

26

27

28

29

30

31

32

33

34

35

36

37

38

39

40

41

42

43

44

45

46

47

48

49

50

51

52

53

54

55

56

57

58

59

60 
Affect Sharing in Infancy
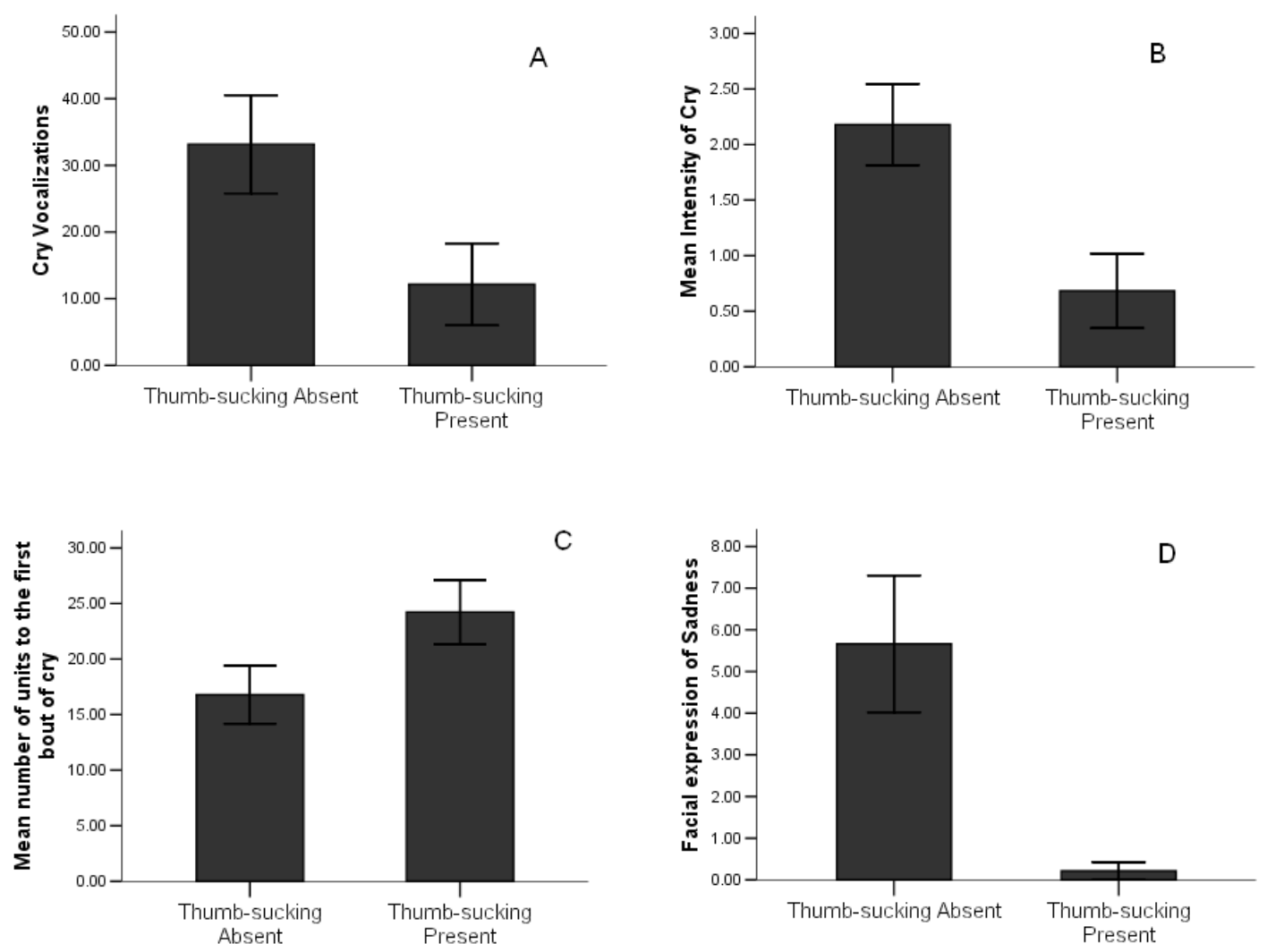
1

2

3

4

5

6

7

8

9

10

11

12

13

14

15

16

17

18

19

20

21

22

23

24

25

26

27

28

29

30

31

32

33

34

35

36

37

38

39

40

41

42

43

44

45

46

47

48

49

50

51

52

53

54

55

56

57

58

59

60

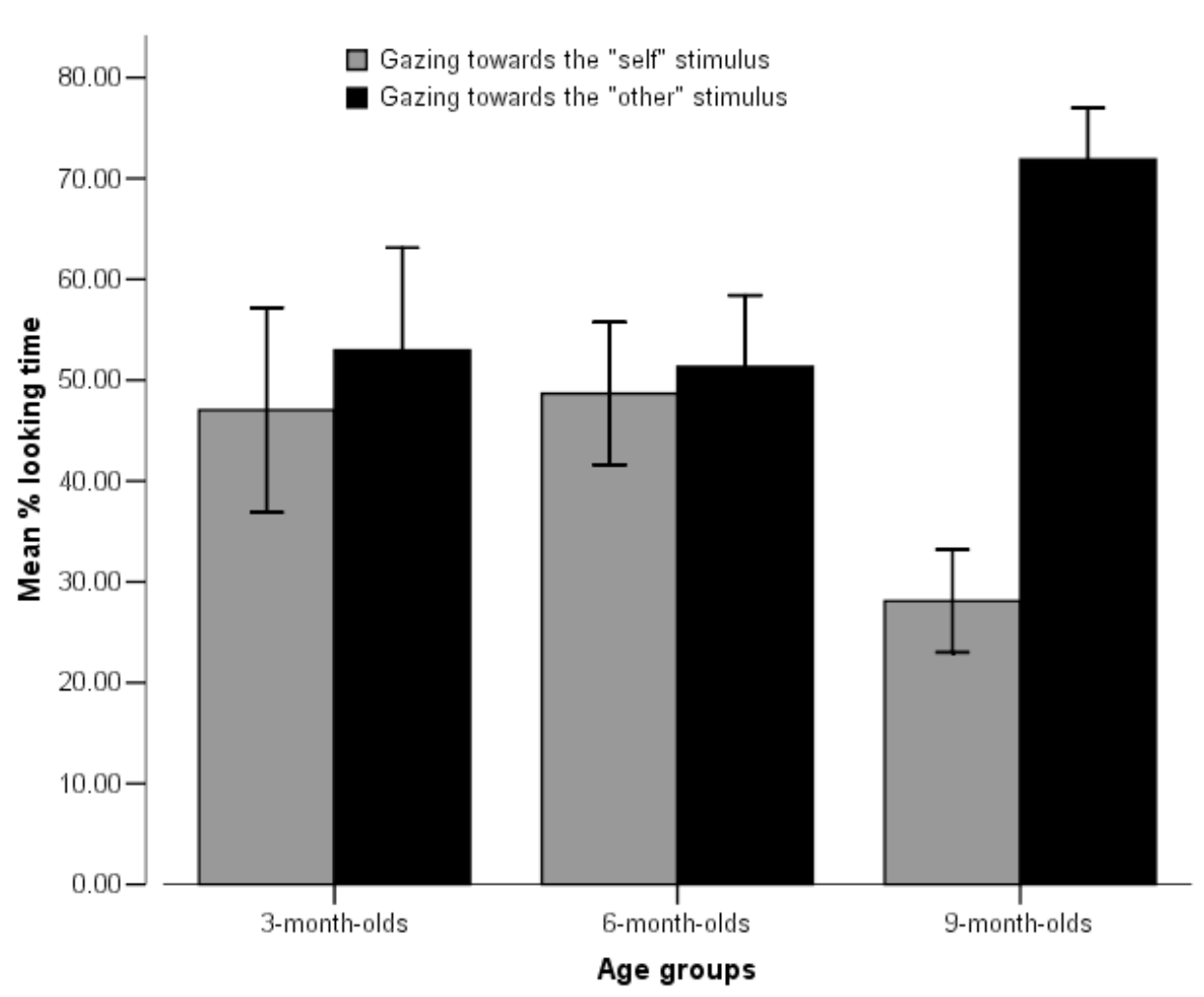

Affect Sharing in Infancy 